\title{
PERAN PERCEIVED ORGANIZATIONAL SUPPORT DAN PSYCHOLOGICAL EMPOWERMENT TERHADAP KINERJA KARYAWAN MELALUI ORGANIZATIONAL CITIZENSHIP BAHAVIOR
}

\author{
Dhera Alfiana \\ Universitas Negeri Surabaya \\ dheraalfiana16080574106@mhs.unesa.ac.id
}

\begin{abstract}
This research mainly explores the relationship between perceived organizational support and psychological empowerment to employee performance and organizational citizenship behavior as mediation variabel. causality research using census is type this reseacrh total of 50 employees of PT. Angkasa Pura I Juanda Surabaya participants in this study. The statistical analysis used PLS with help of smartpls 3.0 software. The result of this study explain that the perceived organizational support and psychological empowerment has a significant effect and positively to organizational citizenship behavior, perceived organizational and psychological empowerment has insignificant effect and positively to employee performance, organizational citizenship behavior has significant effect and positively to employee performance, organizational citizenship behavior as mediation has insignificant effect and positively between perceived organizational citizenshp behavior and psychological empowerment to employee performance.
\end{abstract}

Keywords: employee performance; perceived organizational support; psychological empowerment.

\section{PENDAHULUAN}

Bandar Udara dianggap sebagai pintu gerbang suatu daerah, awal fungsinya hanya sebagai transportasi udara atau sebaliknya, maka sekarang bandara berfungsi menjadi fasilitas kegiatan perdagangan khususnya dalam perdagangan internasional (PT. Angkasa Pura I , 2018). Untuk dapat melaksanakan fungsinya dengan baik maka diperlukan sumber daya manusia yang berkompeten (Saretta, 2019).

Peranan penting pencapaian tujuan perusahaan adalah sumber daya manusia. Meskipun banyak digantikan oleh teknologi yang canggih, tapi sampai sekarang untuk menjalannya proses bisnis perusahaan SDM tetap dianggap sebagai yang utama. Sehingga perusahaan ingin agar setiap sumber daya manusia bekerja dengan efektif dan efisien. Banyak perusahaan berhasil mencapai tujuan karena peran dari pimpinan yang termasuk sumber daya manusia (Wijayanti \& Fazlurrahman, 2018) Sehingga untuk mencapai tujuan maka pengelolaan usmber daya manusia menjadi hal yang penting (Leatemia, 2018) salah satunya adalah PT Angkasa Pura I.

Badan Usaha Milik Negara yang berjalan di bidang sektor transportasi dan pergudangan adalah PT Angkasa Pura I, memiliki kinerja dan pelayanan terbaik menurut situs resmi perusahaannya. Perusahaan ini mengelola 13 bandara di wilayah Indonesia bagian timur. Perusahaan ini sangat peduli terhadap kinerja, kinerja dianggap sebagai nilai akhir dari pencapaian (PT. Angkasa Pura I, 2018).

Kinerja karyawan merupakan suatu prestasi dan juga hasil kerja karyawan secara kualitas kerja serta kuantitas kerja saat melakukan pekerjaannya (Mangkunegara, 2009). Faktor pendorong kinerja salah satunya adalah perceived organizational support (Atmaja, 2019). Menurut wawancara dengan human capital section head, PT Angkasa Pura I Juanda Surabaya memiliki pegawai yang banyak dengan kebutuhan dan status sosial yang bervariasi, hal ini akan mampu memengaruhi persepsi karyawan tentang bagaimana perusahaan mampu menghargai mereka, akibatnya akan menjadi diferensiasi persepsi terhadap karyawan yang berdampak terhadap varitas kerja. Persepsi dari karyawan ini berperan untuk perceived organizational support tiap individu (Chiang \& Hsieh, 2012). Ahmed \& Ali (2015) mendefinisikan perceived organizational support sebagai keyakinan pegawai 
Dhera Alfiana. Peran Perceived Organizational Support dan Psychological Empowerment terhadap Kinerja Karyawan melalui Organizational Citizenship Behavior

tentang seberapa jauh perusahaan mampu menghargai karyawannya serta memperdulikan kesejahteraan karyawan.

Perceived organizational support juga mampu memaksimalkan kinerja karyawan hal ini karena dukungan organisasi terhadap karyawan merupakan efek positif yang akan mendukung sikap karyawan (Casimir \& Wang, 2014). Hal ini membuktikan perceived organizational support memiliki hubungan positif dengan kinerja (Sukmayanti \& Sintaasih, 2018). Karyawan akan melakukan tugas dengan baik apabila merasa didukung oleh perusahaan, daripada pegawai yang dirasa tidak mendapat dukungan organisasi (Fransita, 2016). Hal yang sama juga diungkapkan oleh Mursidta (2017) perceived organizational support pada karyawan yang bekerja di PT. Varia Usaha Beton Gresik memiliki pengaruh signifikan positif ke kinerja karyawannya. Tetapi berbeda dengan Chiang \& Hsieh (2012) menyatakan tidak ada pengaruh perceived organizatinal support ke kinerja karyawan Hotel di Taiwan. Fadlillah (2019) menjelaskan perceived organizational support terhadap organizational citizenship behavior memiliki pengaruh negatif.

Faktor lain yang mendorong kinerja karyawan adalah psychological empowerment (Sukmayanti \& Sintaasih, 2018). Dzia \& Uddin (2016) mengungkapkan banyak perusahaan menggunakan psychological empowerment yang bertujuan untuk menambah motivasi dalam diri karyawan itu sendiri, sehingga dapat mencapai tujuan dari individu maupun organisasi. Psychological empowerment didefinisikan sebagai seperangkat keadaan psikolog karyawan yang mencakup persepsi tentang tingkat otonomi mereka, kemampuan untuk memiliki pengaruh di lingkungan kerja, memiliki kompetensi diri untuk melakukakan pekerjaan, serta memiliki kemampuan untuk menemukan seberapa besar arti dan makna pekerjaannya bagi dirinya sendiri (Olcher, 2015)

Kundu et al (2018) menunjukkan bahwa psychological empowerment yang dilakukan oleh beberapa sektor perbankan di India memiliki pengaruh postif terhadp kinerja karyawan. Sukmayanti dan Sintaasih (2018) menunjukkan psychological empowerment positif ke kinerja karyawan di Bank Pembangunan Daerah di Bali. Tetik (2016) juga menjelaskan psycholgical empowerment berpenggaruh positif ke kinerja karyawan. Tetapi psychological empowerment tidak berpengaruh ke hasil kerja (Zahra, 2017).

Karavardar (2014) meningkatnya kinerja didorong oleh sikap dari OCB. Organizational citizenship behavior didefinisikan sebagai sikap dengan prinsip utama digunakan karyawan yang melaksanakan perilaku tersebut maka akan dapat menaikkan produktifitas kerja. Ini karena sikap dari OCB adalah peran penting pada pertukaran antara organisasi dengan karyawan (Abrar, 2019). Ketika karyawan mengembangkan organizational citizenship behavior di tempat kerja, mereka rela menempatkan usaha ekstra ke dalam pekerjaan, membantu rekan kerja, dan melakukan inovasi dalm pekerjaan sehingga mampu menghasilkan produktifitas yang lebih baik (Adriansyah \& Suryani, 2018).

Lestari et al (2018) mengungkapkan bahwa sikap dari organizational citizenship behavior pada karyawan mampu meningkatkan kinerjanya yang berarti orgainzational citizenship behavior memiliki pengaruh positif ke performance. Penelitian tersebut didukung Ariesta (2016) OCB berpengaruh positive ke kinerja. Penelitian Ismail et al (2018) mengungkapkan bahwa organizational citzenship behavior berpengaruh positive kepada kinerja. Tetapi pada penelitian Haidarzadeh \& Mirvaisi (2013) menunjukkan bahwa perilaku organizational citizenship behavior pada karyawan tidak berpengaruh.

Penelitian tentang organizational citizenship behavior telah banyak dilakukan sebelumnnya. Salah satunya adalah yang dilakukan oleh Karavardar (2014) yang menunjukkan ketika perceived organizational support pada karyawan restoran cepat saji di Istanbul Turki tinggi maka sikap organizational citizenship behavior juga tinggi. Dalam penelitian Sukmayanti (2018 perceived organizational support positif ke organizational citizenship behavior. Namun, hasil berbeda dari penelitian Ihtian (2014) menyatakan perceived organizational support tidak memiliki pengaruh terhadap organizational citizenship behavior. 
Penelitian lain tentang organizational citizenship behavior salah satunya adalah pengaruh pemberdayaan psikologi ke organizational citizenship behavior juga dilakukan oleh Kosar (2017), pada penelitiannya mengatakan bahwa psyclogical empowerment positif ke organizational citizenship behavior. Putri \& Ratnaningsih (2018) yang menyatakan bahwa psychological empowerment positif ke organizational citizenship behavior. Saleem et al (2017) mengungkapkan bahwa psychological empowerment positif ke organizational citizenship behavior pada 18 Universitas sektor publik dan swasta di Pakistan. Singh (2018) yang mengungkapkan bahwa psychological empowerment positif kepada organizational citizenship behavior. Sedangkan pada penelitian Adriansyah dan Suryani (2018) psychological empowerment tidak pengaruh ke sikap organizational citizenship behavior pada PT Telkom Witel Aceh.

Berdasarkan hasil observasi telah diberikan bentuk dukungan dari organisasi melalui beberapa tunjangan agar karyawan merasa lebih sejahtera. Tunjangan tersebut berupa tunjangan kesehatan, tunjangan kelahiran, tunjangan anak, tunjangan pendidikan, dan tunjangan lain. Melalui perceived organizational support yang telah diberikan oleh perusahaan, karyawan menyambut positif dukungan organisasi yang telah diberikan. Menurut keterangan dari human capital officer adanya dukungan tersebut memunculkan perilaku ekstra karyawan, sikap ini muncul saat beberapa karyawan yang melakukan lembur tanpa diminta oleh pimpinan. Hal tersebut dikarenakan karyawan menyadari untuk menyelesaikan tanggung jawab tepat waktu.

Perusahaan juga telah menerapkan psychological empowerment guna meningkatkan kinerja karyawan, pemberiannya melalui pelatihan berkala untuk karyawan yang dilakukan sesuai divisi karyawan dan pelaksanaannya dilakukan secara desentralisasi oleh pusat. Perusahaan juga mengadakan pendidikan pelatihan pada saat orientasi yang dilakukan beberapa tahapan di masa awal kerja guna memperkenalkan proses bisnis perusahaan dan meningkatkan kinerja karyawan.

Pemberian bentuk dari perceived organizational support dan psychological empowerment diharapkan mampu meningkatkan kinerja karyawan, terlebih lagi bentuk dari organizational citizenship behavior telah banyak dilakukan oleh karyawan seperti lembur tanpa diminta oleh atasan, membantu teman yang sedang kesulitan, ataupun menggantikan tugas rekan kerja yang bertugas keluar kota. Hal tersebut sebagai salah satu bentuk kepedulian terhadap perusahaan karna hasil kerja yang ditunjukan mampu meningkatkan pencapaian perusahaan.

Menurut keterangan dari human capital officer sikap dari organizational citizenship behavior tersebut akan berpengaruh ke kinerja karyawan. Evaluasi kinerja karyawan dilakukan setiap tiga bulan yang disebut PMS (Performance Management System). Penilaian kinerja PT. Angkasa Pura I Juanda Surabaya sudah cukup baik tetapi masih bisa terus ditingkatkan, hal ini terbukti bahwa nilai PMS rata-rata karyawan mencapai 3,4.

Penelitian ini bertujuan untuk menguji dan menganalisis hubungan antara perceived organizational support dan psychological empowerment terhadap kinerja melalui organizational citizenship behavior.

\section{KAJIAN PUSTAKA DAN PENGEMBANGAN HIPOTESIS}

\section{Perceived Organizational Support}

Casimir (2014) perceived organizational support ialah suatu persepsi tentang sejauh apa perusahaan akan menilai kontribusi karyawan dan kepedulian mereka pada kesejahteraan karyawan. Menurut penelitian Karavardar (2014) perceived organizational support dijelaskan persepsi tentang seberapa jauh organisasi akan memberikan dukungan kepada karyawan dan kesanggupan organisasi untuk membantu karyawan. Perceived organizational support meliputi meliputi pelakuan yang adil, pengawasan, kondisi kerja yang menguntungkan. (Osman et al. 2015). 
Dhera Alfiana. Peran Perceived Organizational Support dan Psychological Empowerment terhadap Kinerja Karyawan melalui Organizational Citizenship Behavior

Penelitian ini menggunakan indikator milik Casimir et al. (2014) yaitu organisasi menghargai kontribusi, organisasi menghargai usaha ekstra, organisasi akan perhatikan keluhan, organisasi peduli terhadap kesejahteraan, organisasi memperingatkan karyawan, organisasi peduli terhadap kepuasan, organisasi menunjukkan perhatian, dan organisasi akan merasa bangga atas keberhasilan karyawan.

\section{Psychological Empowerment}

Tetik (2016) mengungkapkan bahwa empowerment dianggap sebagai konsep yang sangat penting dalam suatu organisasi karena berpotensi untuk memberikan pengaruh yang menguntungkan bagi individu dan organisasi. Psychological empowerment sebagai motivasi instrinsik yang diwujudkan dalam empat kognisi karyawan terhadap peran pekerjaannya (Kundu, 2018). Menurut Kosar (2017) psychological empowerment merupakan salah satu set kognisi motivasi yang dibentuk dari lingkungan kerja sehingga akan mencerminkan orientasi individu yang aktif terhadap peran pekerjaannya.

Penelitian ini menggunakan indikator dari Spreitzer (1995) dalam Kosar (2017) dengan empat indikator yaitu meaning (kebermaknaan), competence (kompetensi diri), self determination (penentuan diri sendiri), Impact (dampak).

\section{Organizational Citizenship Behavior}

Suatu sikap secara sukarela, tidak diwajibkan oleh organisasi, serta pelaksanaan organizational citizenship behavior juga tidak terkait dengan reward secara langsung, tetapi hal tersebut menjadi bahan pertimbangan dalam promosi (Haidarzade, 2013). Organizational citizenship behavior didefinisikan sebagai kontruk individu yang biasa disebut perilaku pegawai yang melampui kewajiban yang tak secara langsung akan diakui perusahaan, perilaku ini juga memberikan kontribusi untuk efektifitas kerja organisasi (Sukmayanti, 2018). Organizational cititzenship behavior adalah kegiatan sukarela karyawan, yang secara tidak langsung dan yang mampu meningkatkan efektifitas fungsi organisasi Saleem (2018). Penelitian ini menggunakan indikator yang mengacu pada penelitian Saleem (2018) dengan lima indikator yaitu altruism, courtesy, civic virtue, sportmanship, conscientiosness.

\section{Kinerja Karyawan}

Hasil kerja atau prestasi oleh pekerja dalam bentuk kualitas kerja maupun kuantitas kerja untuk melaksanakan pekerjaan dari tanggung jawab yang diberikan (Abrar, 2019). Hal ini sejalan dengan Mathis \& Jackson (2011) yang mengemukakan jika kinerja merupakan hasil scara kualitas kerja maupun kuantitas kerja. Jika dikaitkan dengan kondisi pada perusahaan maka indikator yang digunakan dari Mathis \& Jackson( 2011) yaitu kuantitas, kualitas, ketepatan waktu, kehadiran, dan kerjasama.

\section{Hubungan antar Variabel}

Osman (2015) menjelaskan perceived organizational support positif ke sikap organizational citizenship behavior. Chiang \& Hsieh (2012), Karavardar (2014) bahwa perceived organizational support positif ke organizational citizenship behavior sehingga dalam pertukaran sosial, perceived organizational support mampu meningkatkan keinginan karyawan agar melaksanakan kinerja dengan lebih baik. Pada penelitian Sukmayani \& Sintaasih (2018), Ihtian (2014), Maulan (2017), dan Sutanto (2018) juga menyatakan bahwa perceived organizational support positif ke organizational Citizenship behavior.

H1: Diduga perceived organizational support berpengaruh positif ke organizational citizenship behavior.

Singh \& Singh (2019) Singh (2019) membuktikan psychological empowerment positif kepada organizational citizensip behavior, Saleem (2017) penelitian ini dilakukan ke 180 karyawan di Universitas Pakistan menyatakan bahwa psychological empowerment positif ke organizational citizenshp behavior. Kosar (2017) juga menyatakan bahwa penelitian pada sektor perbankan menunjukkan bahwa ketika menerapkan psychological empowerment hal tersebut membuat karyawan memiliki perilaku organizational citizenship behavior. Pada penelitian Putri et al (2018) juga 
menyatakan bahwa psychological empowerment berpengaruh positif ke organizational citizenship behavior.

\section{H2: Diduga psychological empowerment positif ke organizational citizenship behavior.}

Sikap organizational citizenship behavior digambarkan sebagai bentuk kontribusi perilakuan karyawan secara sukarela, tidak diwajibkan oleh organisasi, serta pelaksanaan organizational citizensip behavior juga tidak terkait dengan reward secara langsung, tetapi hal tersebut menjadi bahan pertimbangan dalam promosi (Sukmayanti, 2018). Ismal \& Iqbal (2018) menunjukkan bahwa seorang karyawan yang melakukan perilaku organizational citizenship behavior akan meningkat kinerjanya. Lestari et al (2018) bependapat bahwa dengan perilaku organizational citizenship behavior akan meningkatkan produktifitas dalam kinerjanya.. Pada penelitian Ariesta (2016), Ismail (2016) Abrar (2019), dan Fransista (2016) bahwa organizational citizenship behavior positif ke kinerja.

H3: Diduga organizational ctizenship behavior positif ke kinerja karyawan.

Pada penelitian Atmaja (2019) menjelaskan bahwa ada hubungan antara persepsi diri karyawan dengan kinerja yang dihasilkan, penelitian tersebut menyatakan bahwa perceived organizational support berpengrauh positif dan signifikan terhadap kinerja karyawan semakin tinggi perceived organizational support maka kinerja juga semakin meningkat. Hal tersebut didukung oleh penelitian dari Sukmayanti (2018), Mursidha (2017) Casimir (2014), Biswan (2019), Putra (2019), Ariarni (2017) dan Ariesta (2016) yang juga menyatakan bahwa perceived organizational support memiliki pengaruh hubungan positif terhadap kinerja karyawan.

H4: Diduga perceived organizational support positif ke kinerja karyawan.

Kundu (2019) menjelaskan pengaruh pemberdayaan psikologis ke kinerja karyawan. Pemberdayaan organisasi yang dilakukan yaitu dengan memberikan informasi secara tepat waktu, pelatihan keterampilan dan dukungan emosional terhadap karyawan perbankan. Hasil ini menunjukkan bahwa psychological empowerment yang diberikan tersebut dapat meningkatkan level kinerja pekerjaan. Didukung oleh Sukmayanti \& Sintaasih (2018) pada 60 karyawan bank di Bali yaitu psychological empowerment berpengaruh signifikan postif ke kinerja kayawan. Tetik (2016) mengungkapkan bahwa menerapkan dan meningkatkan empowerment tidak hanya dari perspektif tetapi juga psikologinya. Hasil penelitian tesebut menunjukkan psychological empowerment postif ke kinerja. Pada penelitian Adriansyah \& Suryani (2018), Sun (2016) dan Dzia \& Uddin (2016) juga menyatakan bahwa psychological empowerment positif ke kinerja.

H5: Diduga psychological empowerment positif ke kinerja karyawan.

Karyawan yang merasa mendapat dukungan akan bekerja lebih baik (Casimir \& Wang, 2014). Pada penelitian Chiang \& Hsieh (2012) pada karyawan hotel di Taiwan menyatakan bahwa organizational citizenship behavior memediasi perceived organizational support dan kinerja. Sukamayanti \& Sintaasih (2018) menyatakan bahwa organizational citizenship behavior memediasi antara perceived organizational citizenship behavior ke kinerja karyawan Bank yang ada di Bali. Penelitian tersebut menyatakan bahwa semakin tinggi presepsi karyawan terkait dukungan dan peran organisasi dalam dirinya maka sikap organizational citizenship behavior juga semakin meningkat sehingga akan meningkatnya hasil kerja pada diri karyawan.

H6: Diduga perceived organizational support berpengaruh ke kinerja karyawan dimediasi organizational citizenship behavior.

Karyawan membutuhkan dukungan psychological empowerment untuk menunjang kemampuannya dalam menyelesaikan (Kundu \& Kumar, 2018). Pada penelitian Sukamayanti \& Sintaasih (2018) menyatakan organizational citizenship behavior mampu menjadi mediasi antara psychological 
Dhera Alfiana. Peran Perceived Organizational Support dan Psychological Empowerment terhadap Kinerja Karyawan melalui Organizational Citizenship Behavior

empowerment ke kinerja pada karyawan Bank yang ada di Bali. Hasil penelitian tersebut menyatakan bahwa semakin tinggi pemberdayaan karyawan maka akan akan menimbulkan sikap organizational citizenship behavior yang nantinya akan meningkatkan kinerjanya. Hubungan antar variabel juga digambarikan di Gambar 1.

H7: Diduga psychological empowerment berpengaruh ke kinerja karyawan dimediasi organizational citizenship behavior.



Gambar 1. KERANGKA KONSEPTUAL

\section{METODE PENELITIAN}

Jenis penelitian ini adalah penelitian kuantitatif yang dilaksanakan di PT. Angkasa Pura I Juanda Surabaya. Populasi yang digunakan adalah karyawan PT. Angkasa Pura I Juanda sebesar 50 karyawan dan besarnya sampel adalah 50 responden. Sensus merupakan teknik pengambilan sample pada penelitian ini. Variabel yang digunakan di penelitian ini adalah adalah variabel independen (X), variabel dependen $(\mathrm{Y})$ dan variabel mediasi $(\mathrm{Z})$. Teknik pengumpulan data melalui observasi dan penyebaran angket atau kuesioner yang disebar secara langsung kepada karyawan PT. Angkasa Pura I Juanda Surabaya. Penyebaran Sumber data diperoleh dari penyebaran kuesioner. Skala pengukuran penelitian ini menggunakan skala likert satu sampai lima. Penelitian ini menggunakan uji validitas dan reliabilitas, uji inner model, dan uji kausalias. Teknik analisis data dilakukan dengan pendekatan Structural Equation Model (SEM) dengan menggunakan metode analisis Patrial Least Square (PLS) yang didukung software komputer smartPLS 3.0

\section{HASIL DAN PEMBAHASAN}

\section{Deskripsi Responden}

Jumlah kuesioner yang dibagikan kepada responden sebanyak 50 kuesioner, kemudian kembali secara keseluruhan dan diolah peneliti sebanyak 50 kuesioner. Berdasarkan data yang diperoleh dari kuesioner didapat karakteristik responden yang meliputi jenis kelamin yang didominasi laki-laki 52, usia yang didominasi usia 26-35 tahun 50\%, status perkawinan didominasi telah menikah $68 \%$, pendidikan didominasi berpendidikan $\mathrm{S} 176 \%$, dan lama berkerja didominasi 1-5tahun sebesar 60\%.

\section{Hasil Statistik Rata-rata}

Perceived organizational support memilik rata-rata nilai 4,025 yang termasuk kedalam kategori ratarata tinggi, variabel psycholgical empowerment sebesar 3,99 yang termasuk ke dalam rata-rata tinggi, variabel organizational citizenship behavior memiliki nilai 4,1 yang termasuk kedalam kategori ratarata tinggi, dan varibel kinerja merupakan kategori tinggi dengan nilai 4,11.

\section{Convergent validity}

Uji validitas dari tiap item di kuesioner mengungkapkan loading factor lebih dari 0,5 berarti setiap item pernyataan dikatakan valid. 


\section{Construct Reliability}

Uji ini dari setiap indikator dengan composite reliabelity apabila di atas 0,70 serta cronbach's alpha pada seluruh konstruk di atas 0,70 yang artinya model variabel tersebut telah sesuai composite reliability dan mempunyai reliabiliti yang baik.

Analisis R-Square

Tabel 1

R-SQUARE

\begin{tabular}{cc}
\hline Variabel & R-Square \\
\hline organizational citizenship behavior & 0,424 \\
Kinerja Karyawan & 0,521 \\
\hline
\end{tabular}

Sumber: Output PLS 3.0

Tabel 1 menunjukkan bahwa perceived organizational support dan psychological empowerment ke organizational citizenship behavior memberikan nilai R-Square sebesar 0,424. Hal ini menjelaskan konstruk organizational citizenship behavior 42,4\% sedangkan $57,6 \%$ dijelaskan oleh variabelvariabel lain yang tidak termasuk dalam penelitian ini. Kemudian pada tabel di atas juga menunjukkan pengaruh perceived organizational support dan psychological empowerment ke kinerja karyawan memberikan nilai R-Square 0,521. Hal ini dapat menjelaskan bahwa variabel konstruk kinerja karyawan sebesar $52,1 \%$ sedangkan $47,9 \%$ dijelaskan oleh variabel-variabel lain yang tidak termasuk dalam penelitian ini

\section{Uji Kausalitas}

Penggunaan inner model bertujuan menganalisis pengaruh antara konstruk, significant di tabel path coefficientce serta gambar hasil indirect effect seperti di bawah ini:

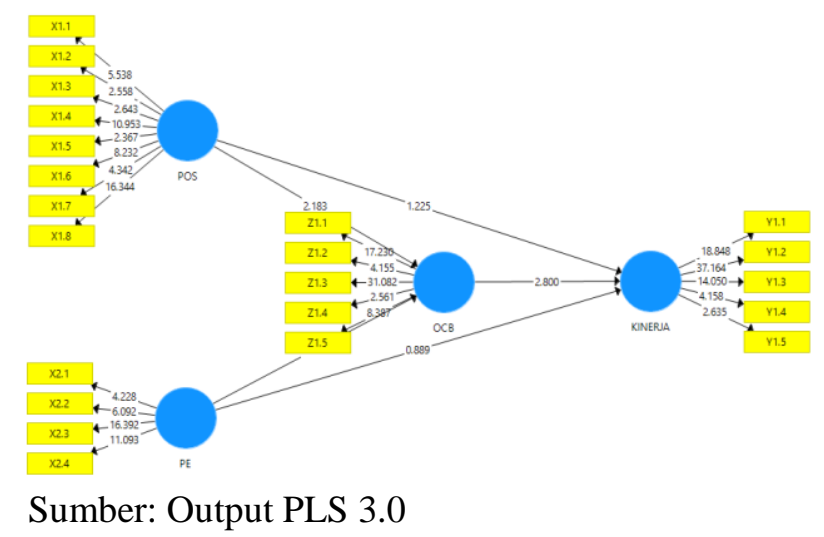

Gambar 2. HASIL DIAGRAM PATH

Gambar 2 menunjukkan nilai dari masing-masing hubungan, hubungan perceived organizational support terhadap organizational citizenship behavior nilainya adalah 2,183 yang artinya hipotesis diterima dan memiliki hubungan. Hubungan psychological empowerment terhadap organizational citizenship behavior nilainya adalah 2,247 yang berarti hipotesis diterima dan memiliki hubungan. Hubungan organizational citizenship behavior terhadap kinerja bernilai 2,800 yang artinya hipotesis diterima dan memiliki hubungan. Hubungan perceived organizational support terhadap kinerja 1,225 hipotesis ditolak dan tidak memiliki hubungan. Hubungan psychological empowerment terhadap kinerja bernilai 0,889 yang berarti tidak ada hubungan sehingga hipotesis ditolak. Seluruh item pada penelitian ini juga valid dan reliable. Tabel 2 menunjukkan bahwa hipotesis 1 dan hipotesis 2 diterima, sedangkan hipotesis lainnya ditolak. Hal ini dikarenakan nilai yang dihasilkan kurang dari 1,96 
Dhera Alfiana. Peran Perceived Organizational Support dan Psychological Empowerment terhadap Kinerja Karyawan melalui Organizational Citizenship Behavior

Tabel 2.

PATH COEFFICIENT

\begin{tabular}{llll}
\hline $\begin{array}{c}\text { Hubungan Antar } \\
\quad \text { Variabel }\end{array}$ & Origin Sample & T-Statistics & Keterangan \\
\hline POS $\rightarrow$ OCB & 0,336 & 2,183 & $\geq 1,96$ (Signifikan) \\
PE $\rightarrow$ OCB & 0.377 & 2,427 & $\geq 1,96$ (Signifikan) \\
OCB $\rightarrow$ KINERJA & 0,478 & 2,800 & $\leq 1,96$ (Signifikan) \\
POS $\rightarrow$ KINERJA & 0,189 & 1,225 & $\leq 1,96$ (Tidak Signifikan) \\
PE $\rightarrow$ KINERJA & 0,154 & 0,889 & $\leq 1,96$ (Tidak Signifikan) \\
\hline
\end{tabular}

Sumber: Output PLS 3.0

Tabel 3.

Indirect Effect

\begin{tabular}{lclc}
\hline \multicolumn{1}{c}{$\begin{array}{c}\text { Hubungan Antar } \\
\text { Variabel }\end{array}$} & $\begin{array}{c}\text { Origin } \\
\text { Sample }\end{array}$ & T-Statistics & Keterangan \\
\hline POS $\rightarrow$ KINERJA & 0,189 & 1,225 & $\leq 1,96$ (Tidak Signifikan) \\
POS $\rightarrow$ OCB $\rightarrow$ KINERJA & 0,161 & 1,772 & $\leq 1,96$ (Tidak Signifikan) \\
PE $\rightarrow$ KINERJA & 0,154 & 0,889 & $\leq 1,96$ (Tidak Signifikan) \\
PE $\rightarrow$ OCB $\rightarrow$ KINERJA & 0,180 & 1,785 & $\leq 1,96$ (Tidak Signifikan) \\
\hline & Sumber: Output PLS 3.0
\end{tabular}

Sumber: Output PLS 3.0

Dari tabel 3 diketahui bahwa besarnya t-stat POS ke kinerja kurang dari 1,96. Sedangkan pengaruh tidak langsungnya juga kuranag dari 1,96 yang berarti OCB tidak mampu memediasi. besarnya t-stat POS ke kinerja kurang dari 1,96. Sedangkan pengaruh tidak langsungnya juga kuranag dari 1,96 yang berarti OCB tidak mampu memediasi.

\section{Pengaruh Perceived Organizational Support terhadap Organizational Citizenship Behavior}

Analisis statistik melalui hasil path coefficientce, perceived organizational support dengan hasil nilai positif terhadap organizational citizenship behavior. Artinya bahwa perceived organizational citizenship behavior mampu mempengaruhi organizational citizenship behavior.

Pada hasil kuesioner yang disebarkan, organisasi sangat peduli terhadap kesejahteraan karyawan. Fasilitas penunjang pekerjaan diberikan oleh perusahaan dengan baik dan maksimal. Hasil rata-rata nilai indikator tertinggi kedua adalah organisasi memperhatikan karyawan. Menurut wawancara, Pemberian beberapa tunjangan kepada karyawan tunjangan pendidikan, tunjangan kematian, tunjangan kelahiran, tunjangan kesehatan bagi keluarga, dan tunjangan kemahalan dirasa sangat membantu kesejahteraan karyawan.

Hasil penelitian ini adalah H1 diterima, diperkuat dengan hasil penelitian terdahulu milik Osman (2015) menunjukkan perceived organizational support pada karyawan di Malaysia ini berpengaruh ke organizational citizenship behavior. Hal yang sama juga dijelaskan dalam penelitian Sutanto (2018) dan Karavardar (2014) perceived organizational support berpengaruh positif ke organizational citizenship behavior.

\section{Pengaruh Psychological Empowerment terhadap Organizational Citizenship Behavior}

Dari hasil dan analisis statistik melalui hasil path coefficient, psycholgical empowerment positif signifikan ke organizational citzenship behavior. Artinya bahwa psychological empowerment mampu mempengaruhi organizational citizenship behavior.

Pada indikator meaning merupakan indikator tertinggi, bahwa kebermaknaan pekerjaan pada karyawan PT. Angkasa Pura I Kantor Juanda Surabaya sangat tinggi. Menurut hasil wawancara dengan Pak Giga selaku human capital officer, beliau menyatakan telah memaknai pekerjaan yang dikerjakan, beliau juga menyadari bahwa beliau bekerja untuk memenuhi kehidupan kehari-hari serta 
menyadari bahwa pekerjaan yang dikerjakan di unitnya memegang peranan penting bagi PT. Angkasa Pura.

Indikator kedua adalah competence, karyawan PT. Angkasa Pura I Kantor Juanda Surabaya telah merasa memahami dan percaya terhadap kemampuannya untuk menyelesaikan tugas yang diberikan. Hal ini dilakukan dengan adanya diklat yang diadakan oleh seluruh karyawan, pelaksanaan diklat sendiri dilakukan beberapa tahapan, tahapan pertama dilakukan di kantor pusat, tahapan berikutnya dilakukan di tiap bandara operasi masing-masing yang disebut dengan Diklat B\&C. Diklat B\&C bertujuan agar calon pegawai dapat mengerti dan memahami seluruh prosedur bisnis yang ada di PT. Angkasa Pura. Dalam hal tersebut tentunya akan berdampak pada sikap-sikap organizational citizenship behavior yang ada di diri karyawan PT. Angkasa Pura I Juanda Surabaya.

Hasil penelitian ini didukung dilakukan oleh Saleem (2017) juga mengungkapkan bahwa psychological empowerment positif ke organizational citizenship behavior pada 18 Universitas sektor publik dan swasta di Pakistan. Hal ini sama dengan penelitian Kundu (2019) dan Kosar (2017) yang menyatakan bahwa psycological empowerment positif ke organizational citizenship behavior.

\section{Pengaruh Organizational Citizenship Behavior terhadap Kinerja Karyawan}

Hasil analisis statistik yang melalui hasil path coefficient, organizational citizenship behavior positif signifikan ke kinerja. Artinya bahwa organizational citizenship behavior mampu mempengaruhi kinerja karyawan.

Sikap-sikap yang ditunjukkan oleh karyawan terkait perilaku organizational citizenship behavior sudah sesuai. Sikap $O C B$ seperti courtesy (kebaikan) memiliki nilai indikator tertinggi. Hal ini ditunjukkan dengan membangun perilaku baik terhadap karyawan. Berdasarkan hasil observasi karyawan saling mengenal meskipun berbeda unit. Sikap lain yang ditunjukkan adalah apabila ada perbedaan pendapat maka untuk menyelesaikannya tidak dengan cara menyakiti perasaan melainkan dengan berdebat secara professional hingga menghasilkan suatu keputusan yang dapat diterima bersama.

Sikap tertinggi kedua yaitu indikator altruism (kepedulian). Ditunjukkan dengan karyawan yang saling membantu. Menurut hasil wawancara dengan karyawan serta hasil observasi, perilaku altruism berkaitan dengan sukarela agar pekerjaan yang menjadi tanggung jawab suatu unit cepat terselesaikan. Dengan terselesaikannya suatu pekerjaan pada seorang karyawan akan berdampak pada tugas-tugas selanjutnya, sehingga perilaku tersebut dapat memudahkan proses operasional yang ada di perusahaan. Sikap tersebut juga ditunjukkan oleh karyawan dan rekan kerja lainnya dengan melakukan pekerjaan di luar jam kerja karena ada pekerjaan yang harus diselesaikan secara darurat dan keterbatasan waktu.

Pengaruh organizational citizenship behavior ke kinerja karyawan dikatakan berpengaruh karena perilaku organizational citizenship behavior memiliki yang ditunjukkan dengan adanya sikap altruism, courtesy, civic virtue, sportsmanship, conscientiousness yang akan meningkatkan kinerja. Didukung Ismail (2018) bahwa $O C B$ positif ke kinerja 190 karyawan di Universitas yang berbeda di Azad Khashmir Pakistan. Hal serupa juga dijelaskan oleh Abrar (2019) dan Ghaby (2018) yang menyatakan bahwa $O C B$ positif ke kinerja.

\section{Pengaruh Perceived Organizational Support terhadap Kinerja Karyawan}

Dari tabel path coefficient menunjukkan hasil yang positif ke kinerja tetapi nilainya dibawah t tabel. Yang berarti perceived organizational support tidak mampu mempengaruhi kinerja karyawan.

Dari hasil kuesioner yang disebar, didapat bahwa karyawan yang bekerja selama 1-5 tahun sebesar $60 \%$. Dilihat dari pemberian kesejahteraan, karyawan yang bekerja selama 1-5 tahun belum mendapat tunjangan secara penuh. Dari hasil wawancara menyatakan bahwa beberapa saran masih belum dapat direalisaisan oleh perusahaan, hal ini memungkinkan responden masih kurang merasa pemberian 
Dhera Alfiana. Peran Perceived Organizational Support dan Psychological Empowerment terhadap Kinerja Karyawan melalui Organizational Citizenship Behavior

kesejahteraan. Hasil didukung Chiang dan Hsieh (2012) perceived organizational support tidak memiliki pengaruh terhadap 513 karyawan yang bekerja di Taiwan.

\section{Pengaruh Psychological Empowerment terhadap Kinerja Karyawan}

Dari tabel path coefficient menunjukkan psychological empowerment positif ke kinerja, tapi untuk nilai $\mathrm{t}$ statistic menunjukkan hasil yang lebih kecil dari t-tabel sehingga membuktikan bahwa psychological empowerment tidak memiliki pengaruh ke kinerja

Terdapat nilai kategori sedang yaitu indikator impact. Menurut hasil keterangan dari responden, karyawan masih merasa kurang memiliki kendali atas apa yang terjadi di section, mereka masih sangat bergantung kepada rekan kerja yang bekerja cukup lama dan juga pimpinan unit mereka. Hal ini juga terjadi pada saat karyawan mendapatkan masalah pekerjaan, karyawan kurang merasa memiliki hak otonomi pada saat bekerja sesuai dengan keinginan dari setia karyawan dalam menyelesaikan permasalahan atau pekerjaannya. Karena harus mengikuti standart operasional yang ada dan juga atas sepengetahuan dari pimpinan unit atau section.

Diketahui bahwa mayoritas responden bekerja 1-5 tahun. karyawan kurang merasa memiliki hak otonomi pada saat bekerja sesuai dengan keinginan dari setiap karyawan dalam menyelesaikan permasalahan atau pekerjaannya. Karena harus mengikuti standart operasional yang ada dan juga atas sepengetahuan dari pimpinan unit atau section. Penelitian ini sesuai dengan penelitian Zahra (2017) psychological tidak berpengaruh terhadap kinerja karyawan.

\section{Pengaruh Perceived Organizational Support terhadap Kinerja Karyawan melalui Organizational Citizenship Behavior}

Hasil pengujian hipotesis menunjukkan perceived organizational support tidak mampu memediasi antara perceived organizational support ke kinerja karyawan sehingga H6 dalam penelitian ini ditolak.

Jika dikaitkan dengan penelitian, faktor yang memengaruhi kinerja karyawan tidak hanya berasal dari perilaku $O C B$ dan $P O S$. Hal ini dapat dikarenakan beberapa faktor. Seperti mayoritas pada penelitian ini bermasa kerja 1-5 tahun. Diperkuat dengan penelitian Razak (2016) yang menyatakan menjelaskan bahwa faktor yang mendorong organizational citizenship behavior ialah masa kerja, keadilan, gaya kepemimpinan, dan iklim kerja. Selain organizational citizenship behavior motivasi kerja juga dapat mendorong kinerja. Motivasi yang merupakan dorongan dalam diri karyawan untuk berbuat lebih baik sehingga dapat mencapai tujuan perusahaan.

Menurut keterangan human capital officer kinerja karyawan dipengaruhi oleh motivasi dalam diri karyawan itu sendiri. Hal ini dibuktikan dengan karyawan yang lebih rajin dan menyelesaikan pekerjaan tepat waktu akan mendapat penilaian di yang tinggi di PMS dan dapat memengaruhi bonus yang diterima.

Hal ini sejalan saat karyawan memiliki perceived organizational support maka motivasi kerja akan meningkat. Apabila karyawan memiliki peningkatan dalam motivasi kerja maka secara tidak langsung akan mampu meningkatan kinerja karyawan. Yang berarti adanya perceived organizational support yang dimediasi dengan motivasi kerja meningkatkan kinerja karyawan. Didukung Zulkifli (2018) Motivasi kerja mampu memediasi antara perceived organizational support dan Kinerja karyawan.

\section{Pengaruh Psychological Empowerment terhadap Kinerja Karyawan melalui Organizational Citizenship Behavior}

Dari hasil penguian menyatakan bahwa Hipotesis 7 ditolak. Hal ini mengartikan bahwa organizational citizenship behavior tidak mampu memediasi antara psychological empowerment terhadap kinerja karyawan. Dikaitkan dengan penelitian faktor yang mendorong kinerja karyawan tidak hanya berasal dari perilaku organizational citizenship behavior dan psychological empowerment. Ada beberapa karyawan yang tidak sepenuhnya memiliki sikap psychological empowerment dan organizational citizenship behavior. Penerapan psychological empowerment masih 
belum maksimal, terlebih lagi untuk karyawan yang bekerja kurang dari 5 tahun. Hal ini terlihat dari masih kurangnya hak otonomi karyawan dalam menjalankan tugasnya dan dalam pengambilan keputusan Tentu saja hal ini dapat menghambat kinerja pada karyawan.

Menurut hasil wawancara dengan responden, Karyawan yang bekerja 1-5 tahun juga merasa kurang memiliki kendali atas apa yang terjadi di section, hal ini dikarenakan sebagian besar kebijakan diambil oleh pimpinan section. Meskipun hal ini hanya terjadi dibeberapa section, tetapi memiliki pengaruh terhadap penelitian ini. Menurut hasil wawancara kinerja juga tidak hanya dipengaruhi oleh organizational citizenship behavior tetapi dapat dipengaruhi oleh bagaimana dia merasa puas di tempat kerja, dalam hal ini responden beranggapan bahwa apabila karyawan merasa nyaman dalam menjalankan pekerjaannya, kinerja akan meningkat. Kepuasan di tempat kerja juga dengan sendirinya akan memperbaiki sikap psychological empowerment yang dimiliki oleh karyawan. Diperkuat dengan penelitian Adriansyah \& Suryani (2018) bahwa organizational citizenship behavior gagal memediasi psycholgical empowerment dan kinerja PT. Telkom Witel Aceh.

\section{KESIMPULAN}

Hasil penelitian ini memberikan kesimpulan bahwa perceived organizational support positif signifikan ke organizational citizenship behavior, psychological empowerment positif signifikan ke organizational citizenship behavior, organizational citizenship behavior positif signifikan ke kinerja karyawan, perceived organizational support positif tidak signifikan ke kinerja karyawan, psychological empowerment positif tidak signifikan ke kinerja karyawan. perceived organizational support positif tidak signifikan ke kinerja melalui organizational citizenship behavior. Artinya bahwa organizational citizenship behavior tidak mampu memediasi perceived organizational support dan kinerja karyawan, dan psychological empowerment positif tidak signifikan ke kinerja karyawan. Artinya bahwa organizational citizenship behavior tidak mampu memediasi psychological empowerment dam kinerja karyawan.

Kemudian implikasi manajerial pada penelitian ini yaitu perusahaan perlu memberikan hak otonomi dan kebebasan kepada karyawan untuk melaksanakan sendiri pekerjaan serta permasalahan yang dihadapi. Perusahaan hendaknya melakukan komunikasi dengan karyawan dalam penyelesaian masalah dan rencana kerja tugas guna mengoptimalisasi kinerja. Komunikasi juga perlu ditingkatkan guna pertukaran informasi dan masukan dalam pengambilan keputusan dan selalu memberikan dukungan untuk karyawan agar lebih memaksimalkan kemampuan mereka saat bekerja sehingga dapat meningkatkan produktifitas kerja. Rangsangan dapat berupa bimbingan konseling dan lingkungan kerja yang kondusif. Penelitian selanjutnya juga dapat melibatkan variabel lain seperti komitmen organisasi dan kepuasan kerja.

\section{DAFTAR PUSTAKA}

Abrar, U. (2019). Pengaruh Organizational Citizenship Behavior terhadap Kinerja Karyawan pada PT Urchindize cabang Madura. Jurnal Perilaku dan Strategi Bisnis Vol. 7 No.2, 3 - 6.

Adriansyah , \& Suryani, A. I. (2018). pengaruh pemberdayaan psikologis terhadap kinerja karyawan dengan perilaku kewarganegaraan sebagai variabel mediasi pada karyawan PT. Witel Aceh. Jurnal Ilmiah Mahasiswa Ekonomi Manajemen Vo.3 No.4, 2 - 8.

Ariesta, I. C. (2016). pengaruh kecerdasan emosional dan organizatinal citizenship behavior (OCB) terhadap kinerja peternak ayam ras pedaging. jurnal bisnis, manajemen \& perbankan Vol. 2 No.2., 4 .

Atmaja, J. P. (2019). Pengaruh Perceived Organizational Support terhadap Empoyee Performance Melalui Employee Engagemnet CV Sumo Surya Perkasa di Lombok. AGORA, VOL 7 NO:1, 2 -10 . 
Dhera Alfiana. Peran Perceived Organizational Support dan Psychological Empowerment terhadap Kinerja Karyawan melalui Organizational Citizenship Behavior

Casimir, G. N., \& Wang, K. Y. (2014). the relationships amongst leader-member exchange, perceived organizational support, affective commitment, and in-role performance: a social-exchange perspective. Leadershp \& Organization Development Journal Vol.35 No.5., 7.

Chiang, C. F., \& Hsieh, T. S. (2012). The impacts of perceived orgaizational support and psychological empowerment on job performance: The mediating effects of organizational citizenship behavior. international journal of hospitality management Vol 31, 180 - 190.

Dzia, D. N., \& Uddin. (2016). Psychological Empowerment, Motivation, and Job Performance Amongst 5-Star Hotel Employees in Kuala Lumpur. Journal of Hospitality and Networks Volume 1., 3 - 12.

Fadlillah, C. (2019). pengaruh perceived organizational support dan keadilan organisasional terhadap organizational citizenship behavior melalui kepuasan kerja. Jurnal Ilmu Manajemen Vol.7 No.2.

Haidarzadeh, K., \& Mirvaisi, M. (2013). A survey on impact of emotional intelligence, organizational citizenship behaviors and job. Management Science Letters 3, 5 - 10.

Ihtian, H. (2013). Pengaruh Persepsi Dukungan Organisasi dan Pemberdayaan Psikologis Terhadap Kinerja yang dimediasi Organizational Citizenship Behavior di Badan Pusat Statistik Provinsi Daerah Istimewa Yogyakarta. jurnal Bisnis Teori dan Implementasi Vol 5. No 1., 1-10.

Ismail, S., \& Iqbal, Z. (2018). Impact of Organizational Justice and Organizational Citizenship Behavior on Employees Performance. International Journal of Human Resource Studies Vol.8 No. 2., 9.

Karavardar, G. (2014). Perceived Organizational Support, Psychological Empowerment, Organizational Citizenship Behavior, Job Performance and Job Embeddedness: A research on the Fast Food Industry in Istanbul Turkey. International Journal of Business and Management Vol:9 No:4.

Kosar, R. (2017). the impact of psychological empowerment on organizational citizenshio behavior and knowledge sharing behavior: the mediating role of employee engagemnt and moderating role of leader member-exchange. Jinnah Business Review Vol. 5 No. 2., 4-7.

Kundu, T. S., \& Kumar, S. (2018). powering leadership and job performance: mediating role of psychological empowerment. leadership and job performance 605, 10 - 12.

Leatemia, S. Y. (2018). pengaruh pelatihan dan pengalaman kerja terhadap kinerja pegawai (Studi Pada Kantor Badan Pusat Statistik di Maluki. Jurnal Manis, 1-10.

Lestari, E. Y., \& Ghaby, N. K. (2018). pengaruh organizational citizenship behavior (OCB) terhadap kepuasan kerja dan kinerja karyawan. industrial. Jurnal Teknologi dan Manajemen Agroindustri Vol.7 No.2., 5-10.

Mangkunegara, A. P. (2009). Manajemen Sumber Daya Manusia. bandung: Remaja Rosdakarya.

Mathis, \& Jackson. (2011). Human Resource Management. In p. D. Angelica, Human Resource Management. Jakarta: sSalemba Empat.

Mohamed, S. A., \& Ali, M. (2015). The Infuence of Perceived Organizational Support on Employee Job Performance. International Journal of Scientific and Research Publications, Vol 5, 1. 
Mursidta, S. (2017). Pengaruh Perceived Organizational Support dan Kepuasan kerja terhadap Kinerja Karyawan pada PT. Varia Beton Gresik. Jurnal Ilmu Manajemen Vol 5 No 1, 1.

Olcher, F. (2015). mediating effect of job satisfaction in the relationship between psychological empowerment and job performance. Theoretical and applied economics volume XXII, 6-10.

Osman, A. (2015). The Influence of Job Satisfaction, Job Motivation \& Perceived Organizational Support towards Organizational Citizenship Behavior (OCB) A Perspective American-Based Organization. Asian Social Science Vol. 11 No. 21, 4-9.

PT. Angkasa Pura I . (2018). Annual Report . Jakarta.

Putri, P. A., \& Ratnaningsih, I. (2018). Hubungan antara psychological empowerment dengan perilaku kewargaa organisasi pada karyawan perusahaan distributor PT. X. Jurnal Empati Vol.7 No.1., 1.

Saleem, A. (2017). organizational citizenship behavior, psychological empowerment and demographic characteristics: teacher' perspective. international journal of advanced and applied sciences 4(7)., 1.

Singh, S. K., \& Singh, A. P. (2019). Interplay of organizational justice, psychological empowerment, organizational citizenship behavior, and job satisfaction in the context of circular economy. Emerald Insight Vol 57 no 4, 1-10.

Sukmayanti, N. K., \& Sintaasih , D. (2018). The Effect of Perceived Organizational Support and Psychological Empowerment on Job Performance with Organizational Citizenshp Behavior as Mediation. IOSR Journal of Business and Management, Vol 20, 1.

Tetik, N. (2016). The Effect of Psychological Empowerment on ob Satisfaction and Job Performance of Tourist Guides. International Journal of Academic Research in Business and Social Sciences Vol. 6, No.2., 1.

Wijayanti , D., \& Fazlurrahman, H. (2018). The Mediating of Change Organization in the Effect of Strategic Leadership Style and Innovation. International Journal of Academic Research in Business and Social Sciences, 2.

Zahra, H. N. (2017). Studi Kreativitas Dalam Meningkatkan Kinerja Karyawan (Studi Kasus KPP Pratama Surabaya Genteng Dan KPP Pratama Surabaya Gubeng. 15.

Zulkifli, J. (2018). Pengaruh Persepsi Dukungan Organisasional Dan Kemampuan Kerja Terhadap Kinerja Dengan Motivasi Kerja Sebagai Variabel Mediasi. Naskah Publikasi, 1. 